\title{
Comparative study between Ketamine and dexamethasone added to bupivacaine in ultrasound guided infra clavicular brachial plexus block for upper limb surgeries
}

\author{
Bakheet A, Hassan A, Darweesh E, Soliman F. \\ Department of anesthesia and ICU, Sohage University, sohage, Egypt.
}

\section{Background}

the aim of this study is to compare between ketamine and dexamethasone when added to bupivacaine in ultrasound guided infraclavicular brachial plexus block for upper limb surgeries. Methods: The patients were randomly allocated to two groups, 25 patients each: Group K (ketamine group) Patient received $\mathbf{3 0} \mathrm{ml}$ of $\mathbf{0 . 3 7 5 \%}$ bupivacaine plus $\mathbf{0 . 5} \mathrm{mg} / \mathrm{kg}$ ketamine in $\mathbf{2} \mathrm{ml}$ saline Group D (dexamethasone group) Patient received $\mathbf{3 0} \mathrm{ml}$ of $\mathbf{0 . 3 7 5}$ bupivacaine plus $\mathbf{8} \mathrm{mg}$ dexamethasone in $\mathbf{2} \mathrm{ml}$. Results: Onset time of sensory and motor blocks was significantly decreased in dexamethasone group in comparison with the ketamine group. The visual analogue scale was significantly lower in patients who received dexamethasone versus patients who received local anesthetics and ketamine. The duration of analgesia and resolution of motor block were significantly prolonged in dexamethasone group as compared to ketamine group. Postoperative analgesic consumption was reduced significantly in dexamethasone group as compared with ketamine group. Conclusion: The addition of dexamethasone to bupivacaine resulted in significant reduction in onset time of sensory and motor blocks, prolonged duration of post-operative analgesia, lower analgesic consumption and lower incidence of complications.

\section{Introduction}

Brachial plexus block is a popular and widely employed regional block technique for perioperative anesthesia and analgesia for surgeries of the upper extremity. ${ }^{1}$ Ultrasound guidance has improved the success and decreased the complication rate in regional anesthesia in general. The use of twodimensional ultrasonic imaging to localize the brachial plexus has been highly successful in several approaches. ${ }^{2}$ Nowadays, different drugs have been used with local anesthetics to achieve quick, dense and prolonged block. Drugs like epinephrine, morphine, pethidine, clonidine, butorphanol, midazolam are used along with local anesthetics for this purpose. However these drugs associated with side effects like sedation, respiratory depression, psychomimetic effects, pruritus etc ${ }^{5}$. Drugs with minimal side effects and prolonged duration of analgesia are always looked for. Dexamethasone increases the activity of inhibitory potassium channels on nociceptive $\mathrm{C}$ fibers (via glucocorticoid receptors), thus decreasing their activity .Central, regional, and local anesthetic and analgesic properties have been reported for ketamine. Intravenous (IV) administration of low-dose ketamine decreases postoperative opioid use and improves analgesia. The addition of ketamine to epidural lidocaine or bupivacaine increases the duration of regional anesthesia and postoperative analgesia. It has been seen that peri-incisional use of $\mathbf{0 . 3}$ 0.5\% ketamine combined with local anesthetic in surgical wounds enhances analgesia by a peripheral mechanism. ${ }^{7}$

Patients and Methods

After approval of ethical committee in sohag university hospital, and written 
informed consent, $\mathbf{5 0}$ patients aged 1860 years with ASA I- II who were scheduled for upper limb surgeries under ultrasound guided infraclavicular brachial plexus block were enrolled in the study, we exclude the patients with hypersensitivity to amide local anesthetics or additives. Local infection at the site of injection. Patients with peripheral neuropathy. Coagulopathy and Patients refused the study protocol. The patients were randomly allocated to two groups, 25 patients each: Group K (ketamine group):Patient received $\mathbf{3 0} \mathrm{ml}$ of 0.375\% bupivacaine plus $0.5 \mathrm{mg} / \mathrm{kg}$ ketamine in $\mathbf{2} \mathrm{ml}$ saline. Group D (dexamethasone group): Patient received $30 \mathrm{ml}$ of $\mathbf{0 . 3 7 5}$ bupivacaine plus $8 \mathrm{mg}$ dexamethasone in $2 \mathrm{ml}$ .After arrival to the anesthetic room, the peripheral intravenous (IV) line was placed in the non-operative upper limb and an infusion started with normal saline. Supplemental oxygen (4 $\mathrm{L} /$ minute, was delivered by nasal cannula and routine anesthesia monitoring, including noninvasive arterial blood pressure, heart rate, and pulse oximetry were applied. Pethidine 50mg administered intravenously to all the patient as a premedication just before the block. The skin of the infraclavicular region was disinfected with a $\mathbf{1 0 \%}$ povidone-iodine solution we use a SonoScape ultrasound machine, with a linear high frequency (8-13 MHz) under complete aseptic conditions. The block was performed with the patient in supine position with the head turned away from the side to be blocked. The arm is abducted to $\mathbf{9 0}^{\circ}$ and the elbow flexed. The coracoid process is an important landmark and can be easily identified by palpating the bony prominence just medial to the shoulder while the arm is elevated and lowered. As the arm is lowered, the coracoid process meets the fingers of the palpating hand.
Scanning begins just medial to the coracoid process and inferior to the clavicle. The transducer was positioned in the parasagittal plane to identify the axillary artery. This may require adjustment of the depth, depending on the thickness of the patient's chest wall musculature. The axillary artery was typically seen between $\mathbf{3}$ and $\mathbf{5} \mathrm{cm}$. Once the artery is identified, an attempt was made to identify the hyper echoic cords of the brachial plexus and their corresponding positions relative to the artery; The needle was inserted in-plane from the cephalic aspect, with the insertion point just inferior to the clavicle. The needle was aimed toward the posterior aspect of the axillary artery and passes through the pectoralis major and minor muscles. After careful aspiration, $\mathbf{1}$ to $\mathbf{2} \mathrm{mL}$ of local anesthetic was injected to confirm the proper needle placement and spread. The total volume of injectate is $\mathbf{3 2} \mathrm{ml}$ in each group .in ketamine group we will inject $30 \mathrm{ml}$ bupivacaine $\mathbf{0 . 3 7 5 \%}$ plus 2ml normal saline containing ketamine dose but in dexamethasone group we will inject $\mathbf{3 0} \mathrm{ml}$ bupivacaine $\mathbf{0 . 3 7 5 \%}$ plus $8 \mathrm{mg}$ dexamethasone in $\mathbf{2}$ $\mathrm{ml}$ volume. The injectate would spread cephalic and caudal to cover the lateral and medial cords. The following parameters were assisted after institution of the blockade: Onset and duration of sensory block. Onset and duration of motor block. Duration of post operative analgesia and total consumption of analgesics. Side effect and complication if present. Sensory blockade was tested using pin prick method along the distribution of the four nerves (median nerve, radial nerve, ulnar nerve and Musculocutaneous nerve) compared with contra lateral limb as a reference. $\mathbf{0}=$ normal sensation, $\mathbf{1}=$ loss of sensation of pinprick, $2=$ loss of sensation of touch .Onset of sensory blockade is considered as the time 
SOHAG MEDICAL JOURNAL Comparative study between Ketamine and dexamethasone

interval between the end of local anesthetic administration and loss of sensation to pin prick. The duration of analgesia is defined as the time interval between the ends of local anesthetic administration to the time when patient had VAS (Visual analogue scale) score of $\geq 4$. Motor blockade assessment was done using the Modified Bromage scale for upper extremities on a three point scale.

Modified Bromage Scale (Three Point Scale):

1. Grade $\mathbf{0}=$ normal motor function with full flexion/extension of elbow, wrist and fingers.

2. Grade $\mathbf{1}=$ decreased motor strength with ability to move fingers and/or wrist only.

3. Grade $\mathbf{2 =}$ complete motor blockade with inability to move fingers.

Onset of motor blockade is considered as the time interval between the end of local anesthetic administration and inability to move fingers. The duration of motor blockade is defined as the time interval between the end of local anesthetic administration and the recovery of complete and motor function of the hand. The surgery was allowed to proceed when complete anesthesia was achieved. Intra operatively HR, NIBP, SPO2 were monitored every 5 minute. Post operatively, motor blockade and VAS score were assessed at 4, 8, 16, 18, 19, 20, 21, 22, 23, 24hr. The first request for analgesics and total pethidine dose was documented. Statistical analysis of The data obtained analyzed using statistical program for social sciences (SPSS) version 16.All parametric data (continuous or discrete) obtained from age and hemodynamic variations were analyzed using student $t$-test. Evaluation of non-parametric data (nominal or ordinal) was analyzed using Chi square test. P Value $<\mathbf{0 . 0 5}$ was considered significant.

\section{Results}

Patient charachteristics.

\begin{tabular}{|l|l|l|l|}
\hline & Dexamethasone group & Ketamine group & p.value \\
\hline Age & $\mathbf{3 2 . 1 6} \pm 13.047$ & $\mathbf{3 5 . 6 4} \pm 12.851$ & $\mathbf{0 . 3 4 7}$ \\
\hline weight & $\mathbf{8 1 . 9 2} \pm 9.442$ & $\mathbf{8 4 . 5 6} \pm 10.429$ & $\mathbf{0 . 3 5 3}$ \\
\hline Gender M/F & $21 / 4$ & $\mathbf{1 7} / 8$ & $\mathbf{0 . 1 8 5}$ \\
\hline
\end{tabular}

Table (1) Patient characteristics. "Data presented as mean $\pm \mathrm{SD}$ (standard deviation), $\mathrm{M} / \mathrm{F}$ (male /female). The demographic data was similar in the two groups $\mathrm{p}$ value $>0.05$

Perioperative data of the study groups.

\begin{tabular}{|l|l|l|l|}
\hline & Dexamethasone group & Ketamine group & p.value \\
\hline $\begin{array}{l}\text { Surgery } \\
\text { Duration (hr) }\end{array}$ & $\mathbf{2 . 4 6} \pm \mathbf{0 . 5 3 9}$ & $\mathbf{2 . 4 4} \pm \mathbf{0 . 4 8 6}$ & $\mathbf{0 . 8 9 1}$ \\
\hline $\begin{array}{l}\text { Onset of Sensory } \\
\text { Block (min) }\end{array}$ & $\mathbf{1 7 . 6 8} \pm \mathbf{2 . 8 0 6}$ & $\mathbf{2 8 . 0 0} \pm \mathbf{2 . 9 1 5}$ & $<\mathbf{0 . 0 0 1}$ \\
\hline $\begin{array}{l}\text { Onset of Motor } \\
\text { Block (min) }\end{array}$ & $\mathbf{3 2 . 1 6} \pm \mathbf{4 . 3 2 7}$ & $\mathbf{4 0 . 6 0} \pm \mathbf{3 . 8 9 4}$ & $<\mathbf{0 . 0 0 1}$ \\
\hline $\begin{array}{l}\text { Analgesia } \\
\text { Duration }\end{array}$ & $\begin{array}{l}\mathbf{1 2 5 5 . 2 0} \pm 94.742 \\
\mathbf{( 2 0 . 9} \mathbf{h r})\end{array}$ & $\begin{array}{l}\mathbf{8 6 2 . 5 2} \pm \mathbf{1 0 6 . 5 2 9} \\
\mathbf{( 1 4 . 4 h r )}\end{array}$ & $<\mathbf{0 . 0 0 1}$ \\
\hline $\begin{array}{l}\text { Motor block } \\
\text { Duration }\end{array}$ & $\begin{array}{l}\mathbf{1 0 2 3 . 6 4} \pm \mathbf{1 0 3 . 5 6 2} \\
\mathbf{( 1 7 . 0 6 h r )}\end{array}$ & $\begin{array}{l}\mathbf{7 3 8 . 0 0} \pm \mathbf{1 0 8 . 2 4 4} \\
\mathbf{( 1 2 . 3 h r )}\end{array}$ & $<\mathbf{0 . 0 0 1}$ \\
\hline
\end{tabular}


SOHAG MEDICAL JOURNAL Comparative study between Ketamine and dexamethasone

Table (2) perioperative data of the study groups."Data presented as mean $\pm \mathrm{SD}$ (standard deviation). $\mathrm{Min}=$ minute. $\mathrm{Hr}=$ hour

The onset of sensory and motor block was much less in the dexamethasone group compared to the ketamine group with a highly significant difference in both of them, $\mathrm{p}$ value $<\mathbf{0 . 0 5}$. Meanwhile, the sensory and motor duration were significantly higher among dexamethasone group compared to ketamine group, $\mathrm{p}$ value $<\mathbf{0 . 0 5}$.

\section{Hemodynamic parameters:}

Pulse rate between the two groups.

\begin{tabular}{|l|l|l|l|}
\hline Time & Dexamethasone group & Ketamine group & p.value \\
\hline 1 min & $\mathbf{8 3 . 8 4} \pm \mathbf{8 . 1 3 8}$ & $\mathbf{8 6 . 5 2} \pm \mathbf{1 1 . 4 7 1}$ & $\mathbf{0 . 3 4 5}$ \\
\hline $5 \mathrm{~min}$ & $\mathbf{8 1 . 4 4} \pm \mathbf{6 . 9 0 5}$ & $\mathbf{8 2 . 4 0} \pm \mathbf{8 . 4 3 6}$ & $\mathbf{0 . 6 6 2}$ \\
\hline $10 \mathrm{~min}$ & $\mathbf{7 9 . 4 8} \pm \mathbf{5 . 6 9 4}$ & $\mathbf{7 8 . 6 0} \pm \mathbf{8 . 4 4 1}$ & $\mathbf{0 . 6 6 8}$ \\
\hline 15 min & $\mathbf{7 7 . 2 0} \pm \mathbf{5 . 1 4 8}$ & $\mathbf{7 5 . 8 0} \pm \mathbf{8 . 0 0 0}$ & $\mathbf{0 . 4 6 5}$ \\
\hline 30min & $\mathbf{7 6 . 2 0} \pm \mathbf{4 . 2 8 2}$ & $\mathbf{7 5 . 5 6} \pm \mathbf{7 . 2 1 7}$ & $\mathbf{0 . 7 0 5}$ \\
\hline 60min & $\mathbf{7 8 . 5 2} \pm \mathbf{4 . 4 2 6}$ & $\mathbf{7 6 . 5 6} \pm 9.251$ & 0.344 \\
\hline $120 \mathrm{~min}$ & $\mathbf{8 0 . 2 4} \pm \mathbf{4 . 6 3 9}$ & $\mathbf{8 0 . 0 0} \pm 9.605$ & 0.911 \\
\hline
\end{tabular}

Table (3) Pulse rate between the two groups. "Data presented as mean \pm SD (standard deviation).

This table shows that pulse rate decreased in both groups in the first $\mathbf{3 0}$ minutes and then started to increase again in the following $\mathbf{9 0}$ minutes. The differences between the two groups were non significant throughout the follow up period of $\mathbf{1 2 0}$ minutes.

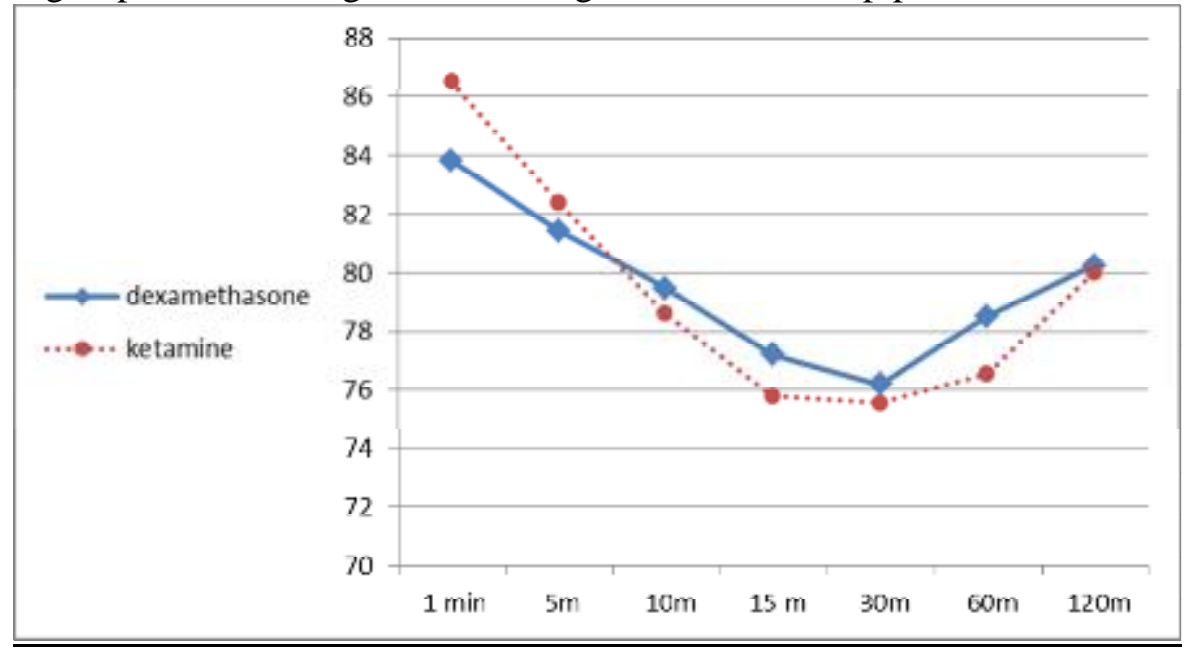

Figure (1) pulse rate between two groups. 
SOHAG MEDICAL JOURNAL Comparative study between Ketamine and dexamethasone

Mean arterial blood pressure.

\begin{tabular}{|l|l|l|l|}
\hline Time & Dexamethasone group & Ketamine group & p.value \\
\hline $1 \mathrm{~m}$ & $92.12 \pm 8.253$ & $89.24 \pm 9.628$ & 0.262 \\
\hline $5 \mathrm{~m}$ & $87.68 \pm 6.568$ & $85.68 \pm 8.050$ & 0.341 \\
\hline $10 \mathrm{~m}$ & $82.20 \pm 7.257$ & $80.72 \pm 7.374$ & 0.478 \\
\hline $15 \mathrm{~m}$ & $83.28 \pm 7.168$ & $79.68 \pm 7.122$ & 0.581 \\
\hline $30 \mathrm{~m}$ & $83.64 \pm 8.169$ & $84.12 \pm 6.747$ & 0.822 \\
\hline $60 \mathrm{~m}$ & $85.24 \pm 7.634$ & $91.08 \pm 6.952$ & 0.844 \\
\hline $120 \mathrm{~m}$ & $92.48 \pm 4.360$ & $94.12 \pm 4.531$ & 0.198 \\
\hline
\end{tabular}

Table (4) Mean arterial blood pressure."Data presented as mean \pm SD (standard deviation)

This table shows that MAP started to decrease in both groups in the first $\mathbf{3 0}$ minutes and then increased again in the following 90 minutes. However, it takes longer time in the dexamethasone group to return to its baseline (120 minutes) compared to only $\mathbf{6 0}$ minutes in the ketamine group. Moreover, it exceeded its baseline level in the ketamine group only after $\mathbf{1 2 0}$ minutes, with no significant difference between two groups $\mathrm{p}$ value $\mathbf{>} \mathbf{0 . 0 5}$.

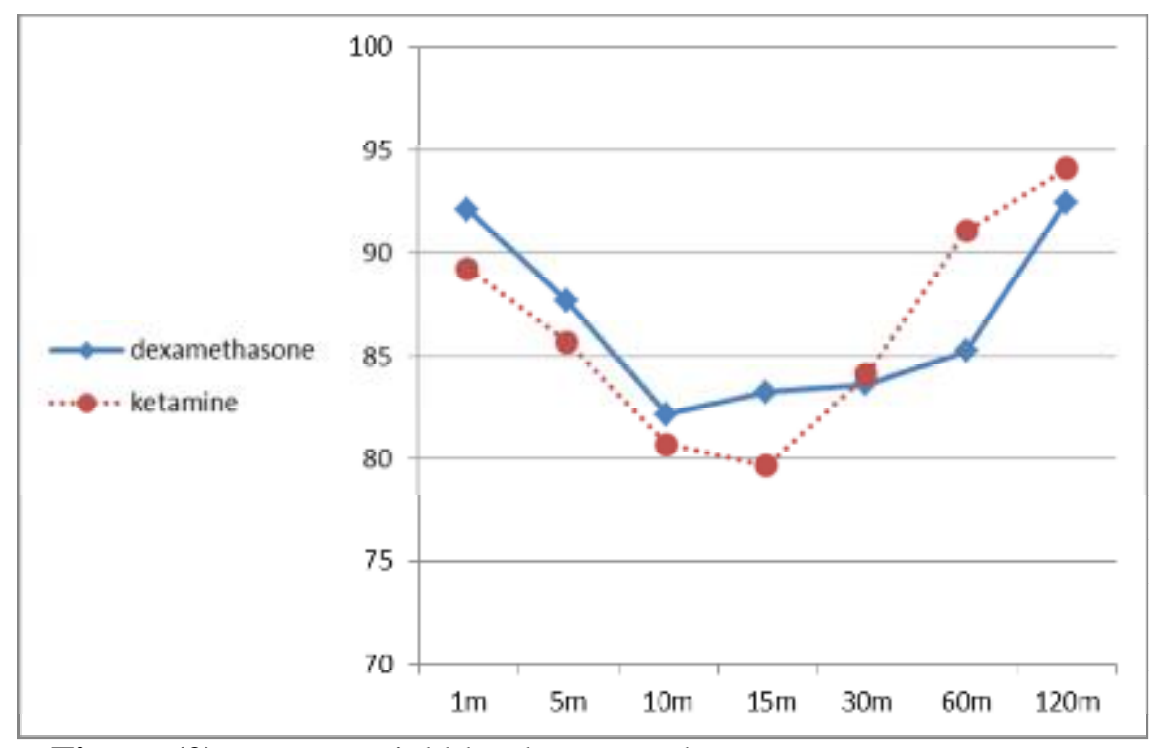

Figure (2) mean arterial blood pressure between two groups 
SOHAG MEDICAL JOURNAL Comparative study between Ketamine and dexamethasone

Post operative VAS.

\begin{tabular}{|l|l|l|l|}
\hline Time & $\begin{array}{l}\text { Dexamethasone } \\
\text { group }\end{array}$ & Ketamine group & p.value \\
\hline $4 \mathrm{~h}$. & $0.00 \pm 0.000$ & $0.00 \pm 0.000$ & - \\
\hline $8 \mathrm{~h}$ & $0.00 \pm 0.000$ & $0.08 \pm 0.400$ & 0.327 \\
\hline $16 \mathrm{~h}$ & $0.80 \pm 1.118$ & $4.92 \pm 1.152$ & $<0.001$ \\
\hline $18 \mathrm{~h}$ & $1.96 \pm 1.513$ & $6.16 \pm .987$ & $<0.001$ \\
\hline $19 \mathrm{~h}$ & $2.56 \pm 1.873$ & $6.32 \pm 1.108$ & $<0.001$ \\
\hline $20 \mathrm{~h}$ & $3.20 \pm 1.708$ & $6.72 \pm 1.137$ & $<0.001$ \\
\hline $21 \mathrm{~h}$ & $4.36 \pm 1.705$ & $7.60 \pm 1.291$ & $<0.001$ \\
\hline $22 \mathrm{~h}$ & $5.32 \pm 1.842$ & $7.68 \pm 1.249$ & $<0.001$ \\
\hline $23 \mathrm{~h}$ & $6.44 \pm 2.162$ & $8.16 \pm 1.143$ & $<0.001$ \\
\hline $24 \mathrm{~h}$ & $7.20 \pm 2.082$ & $8.80 \pm 1.000$ & $<0.001$ \\
\hline
\end{tabular}

Table (5) Post operative VAS.VAS= visual analogue scale. Data presented as mean \pm SD (standard deviation)

This table shows that in the first $\mathbf{4} \mathrm{hr}$ postoperative the VAS was similar in both groups and it increased steadily in both groups with time. However, the VAS was always less in the dexamethasone group compared to that of ketamine group, with significant to highly significant differences, $\mathrm{p}$ value $<\mathbf{0 . 0 0 1}$.

Time of administration of the first dose of rescue analgesics and total dose of pethidine .

\begin{tabular}{|l|l|l|l|}
\hline & Dexamethasone group & Ketamine group & p.value \\
\hline $\begin{array}{l}\text { Time of First Dose } \\
\text { of Rescue } \\
\text { Analgesia(hrs) }\end{array}$ & $20.96 \pm 1.567$ & $13.32 \pm 1.725$ & $<0.001$ \\
\hline $\begin{array}{l}\text { Analgesia Dose in } \\
24 \mathrm{hr}(\mathrm{mg})\end{array}$ & $56.00 \pm 39.051$ & $166.00 \pm 45.000$ & $<0.001$ \\
\hline
\end{tabular}

Table (6) Time of administration of the first dose of rescue analgesics and total dose of pethidine. Data presented as mean $\pm \mathrm{SD}$ (standard deviation) ${ }^{\mathrm{ee}} \mathrm{Hr}=$ (hours) The time of first dose of rescue analgesia was $\mathbf{2 1}$ hours post operatively in dexamethasone group and only $\mathbf{1 3}$ hours in ketamine group, the difference was highly significant with $\mathrm{p}$ value $<\mathbf{0 . 0 0 1}$. This was reflected on the very much higher analgesia dose needed in the first $\mathbf{2 4}$ hours for ketamine group (with a mean of $\mathbf{1 6 6} \mathbf{~ m g}$ ) compared to dexamethasone group (only $\mathbf{5 6} \mathrm{mg}$ ). The difference was, again, highly significant $\mathrm{p}$ value $<\mathbf{0 . 0 0 1}$. 
SOHAG MEDICAL JOURNAL Comparative study between Ketamine and dexamethasone

Adverse effects

\begin{tabular}{|l|l|l|l|}
\hline & Dexamethasone group & Ketamine group & P value \\
\hline Bradycardia & 0 & 0 & - \\
\hline Hypotension & 0 & 0 & - \\
\hline Hypoxia & 0 & 0 & - \\
\hline Hematoma & 0 & 0 & - \\
\hline Nausea & $\mathbf{1}(4 \%)$ & $\mathbf{6}(24 \%)$ & $\mathbf{0 . 0 4 9}$ \\
\hline Vomiting & $\mathbf{1 ( 4 \% )}$ & $\mathbf{1 2 ( 4 8 \% )}$ & $\mathbf{0 . 0 0 1}$ \\
\hline $\begin{array}{l}\text { Local anesthetic } \\
\text { toxicity }\end{array}$ & 0 & 0 & - \\
\hline
\end{tabular}

Table (7) adverse effects. Data presented as number of cases and percentage.

This table shows that the only adverse effects recorded in both groups were nausea and vomiting. Both nausea and vomiting occurred in only one case in the dexamethasone group compared to $\mathbf{6}$ and $\mathbf{1 2}$ cases for nausea and vomiting, respectively, in the ketamine groups. The difference was statistically significant $p$ value $<\mathbf{0 . 0 5}$.

\section{Disscution}

Brachial plexus block is a popular and widely employed regional block technique for peri operative anesthesia and analgesia for surgeries of the upper extremity. Regional nerve block avoids the unwanted effects of the anesthetic drugs used during general anesthesia and the stress of laryngoscopy and tracheal intubation. Local anesthetics alone provide analgesia for not more than 4-8hr.Increasing the duration of local anesthetic action is often desirable because it prolongs surgical anesthesia and analgesia. Different additives had been used to prolong regional blockade as dexamethasone, opioid, ketamine...etc. but the results were inconclusive or associated with side effects.

The aim of our study was to compare the effect of dexamethasone (8mg) and ketamine $(\mathbf{0 . 5} \mathrm{mg} / \mathbf{k g})$ when added to bupivacaine in ultrasound guided infraclavicular brachial plexus block for upper limb surgeries as regard onset time of sensory and motor blocks, duration of post-operative analgesia, motor block duration, hemodynamic variability and side effects as nausea, vomiting, hypotension, bradycardia, hematoma, hemothorax and local anesthetics toxicity if present.

Patient demographic data showed that the majority of cases were males and there is no significant difference between the two groups regarding gender of the patients. The mean age of the study groups was around $\mathbf{3 2}$ years in dexamethasone group and $\mathbf{3 5}$ years in ketamine group, with no significant difference. The weight of the study group was slightly higher in ketamine group compared to the dexamethasone group, with no significant difference.

In our study, the onset of sensory and motor block was much less in the dexamethasone group compared to the ketamine group, with a highly significant difference in both of them $p$ value $<$ 0.001. Meanwhile, the analgesia and motor block duration were significantly higher among dexamethasone group compared to ketamine group $\mathrm{p}$ value $<\mathbf{0 . 0 0 1}$.

This comes in agreement with a study done by Vishnu Vardhan et al., 
SOHAG MEDICAL JOURNAL Comparative study between Ketamine and dexamethasone

2014which evaluated the effect of dexamethasone with bupivacaine (dexamethasone group, $28 \mathrm{ml}$ of $\mathbf{0 . 5} \%$ bupivacaine with $\mathbf{8} \mathrm{mg} \quad(\mathbf{2 m l})$ dexamethasone) compared to bupivacaine with Normal Saline (control group, $28 \mathrm{ml}$ of bupivacaine with $\mathbf{2 m l}$ of normal saline) on the duration of the supra clavicular block in 50 patients. They found that the mean duration of analgesia in dexamethasone group was $\mathbf{1 2 7 8 . 8} \pm$ 82.83 minutes (21.3 hrs) whereas in control group it was $\mathbf{4 2 5 . 6} \pm \mathbf{5 3 . 3 1}$ minutes $(\mathbf{7 . 0 8} \mathbf{~ h r s})(\mathbf{p}<\mathbf{0 . 0 0 0 1})$. The mean duration of motor block in dexamethasone group and control group were $\mathbf{1 0 8 2} \pm \mathbf{8 0 . 4 7}$ minutes $\mathbf{( 1 8 . 0 3}$ hrs) and $359.2 \pm \mathbf{5 5 . 4 5}$ minutes (5.98 hrs) respectively $(\mathrm{p}<\mathbf{0 . 0 0 0 1})$. Both these data were highly significant statistically. Mean onset time of sensory and motor blocks was earlier in dexamethasone group compared to the control group. They concluded that addition of dexamethasone to local anesthetic drugs in supraclavicular brachial plexus block significantly prolongs the duration of analgesia and duration of motor block in patients undergoing upper limb surgeries. This comes in agreement with a study done by Cummings et al., 2011, who used a single-injection interscalene block in four groups: (i) ropivacaine: $\mathbf{0 . 5 \%}$ ropivacaine; (ii) bupivacaine: $\mathbf{0 . 5 \%}$ bupivacaine; (iii) ropivacaine and steroid: $\mathbf{0 . 5 \%}$ ropivacaine mixed with dexamethasone $\mathbf{8} \mathrm{mg}$; and (iv) bupivacaine and steroid: $\mathbf{0 . 5 \%}$ bupivacaine mixed with dexamethasone $8 \mathrm{mg}$. Dexamethasone significantly prolonged the duration of analgesia of both ropivacaine and bupivacaine. Dexamethasone prolongs analgesia from interscalene blocks using ropivacaine or bupivacaine, with the effect being stronger with ropivacaine. However, block duration was longer with plain bupivacaine than ropivacaine. Thus, although dexamethasone prolonged the action of ropivacaine more than that of bupivacaine, the combined effect of dexamethasone and either drug produced nearly the same $\mathbf{2 2} \mathrm{hr}$ of analgesia. Our results were supported by a study done by Shrestha et al., 2007 which evaluated the postoperative analgesia following supraclavicular brachial plexus block with tramadol or dexamethasone as an admixture to bupivacaine in upper extremity surgery in $\mathbf{6 0}$ patients undergoing upper extremity surgery under brachial plexus block. One group received tramadol $(\mathbf{2} \mathbf{m g} / \mathbf{k g})$ and the other group received dexamethasone (8 $\mathbf{~ m g}$ ) as an admixture to Bupivacaine. The authors found that there was significantly faster onset of action $(\mathbf{1 4 . 5} \pm \mathbf{2 . 1 0}$ minutes verses $18.15 \pm 4.25$ minutes; $p<0.05)$ and prolonged duration of analgesia (12.75 $\pm \mathbf{5 . 3 3}$ hours verses $\mathbf{3 . 1 6} \pm \mathbf{0 . 4 8}$ hours; $\mathbf{p}<\mathbf{0 . 0 0 1})$ in the dexamethasone group than in the other group. They concluded that dexamethasone with local anesthetic prolongs postoperative analgesia significantly than tramadol $(\mathbf{P}<\mathbf{0 . 0 5})$ when used as admixture to local anesthetic in brachial plexus block in upper extremity surgery. Our study results come in contact with a study done by Mohammadreza et al., 2015, evaluating the effect of co administration of ketamine to lidocaine in the supraclavicular brachial plexus block for patients undergoing elective upper extremity surgery. 60 patients undergoing elective surgery of the elbow, forearm, wrist or hand were included in two groups of $\mathbf{3 0}$ patients each. Group 1 (ketamine group) received $5 \mathrm{mg} / \mathrm{kg}$ lidocaine $\mathbf{1 . 5 \%}$ plus $2 \mathrm{mg} / \mathrm{kg}$ ketamine, Group 2 (control group) received $\mathbf{5} \mathrm{mg} / \mathrm{kg}$ lidocaine $1.5 \%$ and saline. They reported that no significant differences were noted between groups in the onset and 
SOHAG MEDICAL JOURNAL Comparative study between Ketamine and dexamethasone

duration of the motor and sensory blocks.

Our study results come in agreement with a study by Lee., et al $\mathbf{2 0 0 6}$ which was done to determine whether or not ketamine added to ropivacaine in interscalene brachial plexus blockade prolongs postoperative analgesia. Sixty adults scheduled for forearm or hand surgery under the interscalene brachial plexus block were prospectively randomized to receive one of the solutions of the study. Group P received $0.5 \%$ ropivacaine $30 \mathrm{ml}$, group $\mathrm{K}$ received $\mathbf{0 . 5 \%}$ ropivacaine 30ml with 30mg ketamine, and group $\mathrm{C}$ received $\mathbf{0 . 5 \%}$ ropivacaine with 30mg ketamine intravenous. Loss of shoulder abduction, elbow flexion, wrist flexion and loss of pinprick in the C4-7 sensory dermatomes were assessed at 1-min intervals. The duration of the sensory and motor blocks was assessed after operation. Adverse-effects were also recorded. That study suggested that $\mathbf{3 0} \mathbf{m g}$ ketamine added to ropivacaine in the brachial plexus block did not improve the onset or duration of sensory block.

Our results comes in contradict with movafegh et al., 2006 who designed a study to evaluate the effect of dexamethasone added to lidocaine on the onset and duration of axillary brachial plexus block. $\mathbf{6 0}$ patient scheduled for elective hand and forearm surgery under axillary brachial plexus block were included in their study and received either $\mathbf{3 4} \mathrm{ml}$ lidocaine $1.5 \%$ with $2 \mathrm{ml}$ of isotonic saline (control group) or $\mathbf{3 4} \mathbf{~ m l}$ lidocaine $1.5 \%$ with $2 \mathrm{ml}$ of dexamethasone (8 $\mathbf{m g})$ (dexamethasone group). The duration of surgery and the onset times of sensory and motor block were similar in the two groups. The duration of sensory (242 versus $98 \mathrm{~min}$ ) and motor (310 versus $130 \mathrm{~min}$ ) blockade were significantly longer in the dexamethasone than in the control group $\left(\mathrm{P}_{-} \mathbf{0 . 0 1}\right)$. They concluded that the addition of dexamethasone to lidocaine $1.5 \%$ solution in axillary brachial plexus block prolongs the duration of sensory and motor blockade without change in the onset time. In contradict to our study, Simon et al., 2010 made a study to evaluate the effect of addition of dexamethasone to mepivacaine after ultrasound-guided supraclavicular brachial plexus block for patients undergoing upper-limb surgery.45 patients underwent elective hand or forearm surgery under supraclavicular brachial plexus blockade were included and received either $\mathbf{3 0} \mathrm{ml}$ mepivacaine $\quad \mathbf{1 . 5 \%}$ plus dexamethasone $8 \mathrm{mg}(4 \mathrm{mg} / \mathrm{ml})$, or 30 $\mathrm{ml}$ mepivacaine $\mathbf{1 . 5 \%}$ plus $\mathbf{2} \mathrm{ml}$ normal saline. Patient characteristics were similar in the groups. The median duration of analgesia was significantly prolonged in the dexamethasone group compared with the normal saline group. The onset times of sensory and motor block were similar between the groups the addition of dexamethasone to mepivacaine prolongs the duration of analgesia but does not reduce the onset of sensory and motor blockade after ultrasound-guided supraclavicular block compared with mepivacaine alone. The explanation of difference in onset time of sensory and motor blocks may be due to the difference in volume, concentration, type of local anesthetics, the nature of the block and incidence of failure in the study by movafegh et al., 2006.In our study, in the first $\mathbf{4} \mathrm{hr}$ postoperatively the VAS was similar. This may be due to the long lasting effect of local anesthetics .After the first $\mathbf{4} \mathrm{hr}$ postoperatively, VAS increased steadily in both groups with time. However, the VAS was always less in the dexamethasone group compared to that of ketamine group, with significant to highly 
significant differences. This difference became clearly and observed from 16 hr postoperatively until the end point of the study which was (24hr). This comes in agreement with a study done by Shrestha et al., 2007 that found maximum VAS post operative was at 1010 minute (16 hr) compared with control group which is $\mathbf{4 3 5 - 4 5 0}$ minute (7-8 hr).

The study done by Cummings et al., 2011 which was done to determine the effect of dexamethasone, as an adjuvant for either ropivacaine or bupivacaine on the duration of analgesia from interscalene blocks for painful shoulder procedures. The median maximum VRS (verbal rating score) at rest were significantly lower in the bupivacaine plus dexamethasone group compared with saline on postoperative day1. The median maximum VRS with movement on postoperative day 1 were significantly lower in the ropivacaine plus dexamethasone (5 vs. 7, P.value $\mathbf{0 . 0 0 5}$ ) and bupivacaine plus dexamethasone groups (4 vs. 5.5, P.value $\mathbf{0 . 0 1})$ compared with saline.Our study comes in agreement with a study done by Rahimzadeh et al., 2013 compared the analgesic effects of peri-femoral nerve infusion of ketamine plus ropivacaine versus ropivacaine, after operation, in patients who underwent elective knee surgery for repairing the anterior cruciate ligament, under spinal anesthesia. They reported that the addition of ketamine $1 \mathrm{mg} / \mathrm{kg}$ to $\mathbf{0 . 1 \%}$ ropivacaine could not improve postoperative pain relief in the first $\mathbf{4 8}$ hours after the operation.Our study results in contradict with the study of Mohammadreza et al., 2015, which was done to evaluate the effect of co administration of ketamine to lidocaine in the supraclavicular brachial plexus block for patients undergoing elective upper extremity surgery. 60 patients undergoing elective surgery of the elbow, forearm, wrist or hand were included in two groups of $\mathbf{3 0}$ patients each. Group 1 (ketamine group) received $5 \mathrm{mg} / \mathrm{kg}$ lidocaine $\mathbf{1 . 5 \%}$ plus $2 \mathrm{mg} / \mathrm{kg}$ ketamine, Group 2 (control group) received $\mathbf{5} \mathrm{mg} / \mathrm{kg}$ lidocaine $1.5 \%$ and saline. The most significant and highest VAS pain scores were found in the control group at all-time points $(\mathrm{P}<\mathbf{0 . 0 5})$. This may be due to higher dose of ketamine used $2 \mathrm{mg} / \mathrm{kg}$ compared with our dose $\mathbf{0 . 5 m g} / \mathrm{kg}$.In our study, the time of first dose of rescue analgesia was $\mathbf{2 1}$ hours post operatively in dexamethasone group, and only 13 hours in ketamine group, the difference was highly significant. This was reflected on the very much higher analgesia dose needed in the first $\mathbf{2 4}$ hours for ketamine group (with a mean of $166 \mathrm{mg}$ ) compared to dexamethasone group (only $56 \mathrm{mg}$ ). The difference was, again, highly significant.In our study, we found that dexamethasone has an upper hand compared to ketamine and that may be due to its effect as dexamethasone is very potent and highly selective glucocorticoid (Yadav. , et al 2008).Also, dexamethasone induces a degree of vasoconstriction, so one theory is that the drug acts by reducing local anesthetic absorption. (Viera., et al 2010). The degree of motor block measured by modified bromage scale at $\mathbf{4 h r}, \mathbf{8 h r}, \mathbf{1 6 h r}, \mathbf{1 8 h r}, 19 \mathrm{hr}$, 20hr, 21hr, 22hr, 23hr, 24hr, postoperatively demonstrated a significantly more pronounced motor block with dexamethasone group compared with ketamine group at $\mathbf{1 6} \mathbf{~ h r}$ postoperative until the end point of the study which was (24 hr).This is in agreement with a study done be Shrestha et al., 2007, which was done to evaluate the postoperative analgesia and motor block duration following supraclavicular brachial plexus block with tramadol or dexamethasone as an admixture to bupivacaine in upper 
extremity surgery under brachial plexus block. One group received tramadol $(\mathbf{2} \mathbf{m g} / \mathbf{k g})$ and the other group received dexamethasone $(\mathbf{8} \mathbf{~} \mathbf{~ g})$ as an admixture to bupivacaine. They reported that, in tramadol group the mean duration of return of the motor function was after $\mathbf{2 0 2 . 9}$ minutes (4 hr) and in dexamethasone group it was 393 minutes ( $7 \mathbf{~ h r}$ ) after the block was performed. The difference in the regression time of the motor block was found to be statistically significant $(\mathbf{P}<.05)$. Prolonged regression time may cause limitation of the neurological evaluation of the extremity in selected cases. Hemodynamic parameters, as regard pulse rate and mean arterial blood pressure were comparable between two groups and statistically non significant. This comes in agreement with studies done by Vishnu Vardhan et al., 2014, Islam et al., 2014, Simon et al., 2010. The adverse effects recorded in both groups were nausea and vomiting. Both nausea and vomiting occurred in only one case in the dexamethasone group, compared to 6 and 12 cases for nausea and vomiting, respectively, in the ketamine group. The difference was statistically significant. In our study, no local anesthesia toxicity occurred as regard metallic taste, tingling, numbness and convulsions. This comes in contact with Cummings et al,, 2011 who reported no major complications at $\mathbf{1 4}$ days follow up.Tandoc et al., 2011 reported no major complications at one year. Also, Shrestha et al., 2007 reported no major complications at six months follow up However, our results contradict with a study done by Vishnu Vardhan et al., 2014, who reported that incidence of tingling /numbness in the early post-operative period was $\mathbf{8 \%}$ in dexamethasone group which is statistically not significant. The tingling/numbness disappeared few hours post operatively. This may be due to high concentration of bupivacaine $\mathbf{0 . 5 \%}$ compared with our concentration $\mathbf{0 . 3 7 5 \%}$. Parrington et al., 2010, who used mepivacaine $1.5 \%$. as a local anesthetic in his study and reported the most frequent adverse effect in their study of supraclavicular blocks was numbness or tingling in the hand, which was transitory and was not significantly different between dexamethasone and control groups.

\section{Refrences}

1. Bridenbaugh LD. The upper extremity Somatic blockade. In: Cousins MJ. Bridenbaugh PO, eds. neural blockade in clinical anesthesia and management of pain. Philadelphia: J.B. Lippincott, 1988: 387-416.

2. Cummings KC III, Napierkowski DE, Parra-Sanchez I, et al. Effect of dexamethasone on the duration of interscalene nerve blocks with ropivacaine or bupivacaine. $\mathrm{Br} \quad J$ Anaesth 2011; 107: 446-53

3. Kim YJ, Guie YL, Dong YK, Chi HK, Hee-Jung B, Seok H. Dexamethasone added to levobupivacaine improves postoperative analgesia in ultrasound guided interscalene brachial plexus blockade for arthroscopic shoulder surgery. Korean Journ of Anaesth 2012 Feb; 62(2): 130-4.

4. Lee I, Kim W, Kong M, Lee M, Kim N, Choi Y, Lim S. No enhancement of sensory and motor blockade by ketamine added to ropivacaine interscalene brachial plexus blockade. Acta. Anaesthesiol. Scand.2002; 46:821-826.

5. Movafegh A, Razazian M, Hajimaohamadi F, Meysamie A. Dexamethasone added to lidocaine prolongs axillary brachial plexus blockade. Anesth. Analg. 2006; 102:263-267.

6. Patrick J. Technique of brachial plexus block anesthesia. Br J Surge 1940; 27: 734. 
7. Schwemmer U, Papenfuss T, Greim C, and BrederlauJ, Roewer N: Ultrasoundguided interscalene brachial plexus anesthesia: differences in success between patients of normal and excessive weight. Ultraschall Med 27: 245-250 (2006).

8. Shrestha B, Maharjan S, Tabedar S. Supraclavicular brachial plexus block with and without dexamethasone - a comparative study. Kathmandu. Univ. Med. J. 2003; 1 :158-160.

9. Tandoc MN, Fan L, Kolesnikov S, Kruglov A, Nader ND. Adjuvant dexamethasone with bupivacaine prolongs the duration of interscalene block: a prospective randomized trial. $J$ Anesth 2011; 25: 704-9

10. Tverskoy M, Oren M, Vaskovich $M$, Dashkovsky I, Kissin I. Ketamine enhances local anesthetic and analgesic effects of bupivacaine by peripheral mechanism: A study in postoperative patients. NeurosciLett 1996; 215:5-8.
11. Vieira PA, Pulai I, Tsao GC, Manikantan P, Keller B,Connelly NR. Dexamethasone with bupivacaine increases duration of analgesia in ultrasound-guided interscalene brachial plexus blockade. Eur Anaesthesiol 2010; 27: 285-8

12. Vishnu Vardhan A, Vishnu Mahesh Babu B, Sai Naveena Lakshmi B. "Effect of Dexamethasone with Bupivacaine on Duration of Supra Clavicular Block Compared to Bupivacaine with Normal Saline: A Prospective, Randomized and Double Blind Study". Journal of Evolution of Medical and Dental Sciences 2014; Vol. 3,

13. Yadav RK, Sah BP, Kumar P, Singh SN. Effectiveness of addition of neostigmine or dexamethasone to local anaesthetic in providing perioperative analgesia for brachial plexus block: a prospective, randomized, double blinded, controlled study. Kathmandu Univ Med J2008; 6: 302-9 
SOHAG MEDICAL JOURNAL Comparative study between Ketamine and dexamethasone 